\title{
Using portable negative pressure wound therapy devices in the home care setting
}

This article was published in the following Dove Press journal:

Smart Homecare Technology and TeleHealth

9 December 2014

Number of times this article has been viewed

\section{Joshua R Burke \\ Rachael Morley \\ Mustafa Khanbhai}

Academic Surgery Unit, Education and Research Centre, University Hospital of South Manchester, Manchester, UK
Correspondence: Mustafa Khanbhai Academic Surgery Unit, 2nd Floor, Education and Research Centre, University Hospital of South

Manchester, Southmoor Road, Manchester M23 9LT, UK

Tel +44 I6I 49I 5858

Fax +44 I6I 29I 6644

Email mustafa.khanbhai@doctors.org.uk
Abstract: Negative pressure wound therapy (NPWT) is the continuous or intermittent application of subatmospheric pressure to the surface of a wound that improves the wound environment, accelerates healing, and reduces wound closure time. Since its first documented use, this technology has lent itself to a number of adaptations, most notably, the development of portable devices facilitating treatment in the home care setting. With advancing surgical standards, wound healing is an important rate-limiting factor in early patient discharge and often a major cost of inpatient treatment. The efficacy of NPWT in the home care setting has been investigated through rate of wound closure, time in care, and patient experience. Rate of wound closure is the most appropriate primary end point. Much can be gleaned from patient experience, but the future success of portable NPWT will be measured on time in care and therefore cost effectiveness. However, there is a lack of level 1a evidence demonstrating increased efficacy of portable over inpatient NPWT. The development of portable NPWT is an encouraging innovation in wound care technology, and extending the benefits to the home care setting is both possible and potentially more beneficial.

Keywords: portable, negative pressure wound therapy, vacuum-assisted closure, topical negative pressure therapy

\section{Introduction}

Negative pressure wound therapy (NPWT), also known as vacuum-assisted wound closure, vacuum sealing, or topical negative pressure therapy (TNPT), is the continuous or intermittent application of subatmospheric pressure to the surface of a wound. These terms are used interchangeably within the literature. ${ }^{1}$ First documented in 1993 by Fleischmann et al, ${ }^{2}$ this wound therapy modality is a popular treatment option today for both acute and chronic wounds. ${ }^{3}$ Its use has been described in recalcitrant wounds such as pressure sores, ${ }^{4,5}$ radiation ulcers, ${ }^{6}$ degloving injuries, ${ }^{7}$ and a wide variety of wounds with acute or chronic infection. ${ }^{8}$ It has also been used postoperatively in radical mastectomy, ${ }^{9}$ cesarean section, ${ }^{10}$ sternotomy, ${ }^{11}$ nonresolving empyemas, ${ }^{12}$ partialthickness burns, ${ }^{13}$ temporary abdominal closure, ${ }^{14}$ prevention of groin wound infection following pilonidal sinus resection, ${ }^{15}$ and open vascular procedures. ${ }^{16} \mathrm{NPWT}$ in combat injuries sustained in austere environments has also been documented. ${ }^{14}$

This review aims to introduce NPWT, giving a background to the increasing use of portable NPWT. We will look at the mechanism of action, risk and benefits, efficacy studies (including comparisons of hospital and portable NPWT), and patient-focused perspectives on quality of life. For all papers reviewed, we have identified their evidence levels based on the Oxford Center for Evidence-Based Medicine 2011 levels of evidence document. ${ }^{17}$ 


\section{Wound management}

Negative wound pressure systems utilize foam or open-pored gauze dressings made from polyurethane ether. This is cut to the size of the wound margin and secured using an airtight semiocclusive adhesive dressing. One or more access ports are cut out of the adhesive, where suction tubes are placed. These tubes are connected to a disposable collection canister and vacuum suction pump to complete the fluid collection system..$^{18}$ The vacuum system (Figure 1) creates a suction of -50 to $-175 \mathrm{mmHg}$ around the wound bed. The negative pressure may be continuous or intermittent, and this can be checked using a sensing device placed over the foam dressing. Foam volume is reduced by around $80 \%$, evenly over the wound bed, ensuring an environment that promotes drainage and removal of free fluid. ${ }^{19}$ Protection of friable structures within the wound is achieved through an interposition layer such as mesh or petroleum gauze, which is positioned between the foam and the wound bed..$^{18}$ Dressing change and pain management is guided by the individual clinical situation and is beyond the scope of this review.

Within the literature, the most commonly used system in hospital-based randomized controlled trials is the VAC ${ }^{\circledR}$ therapy device (Kinetic Concepts, Inc., San Antonio, TX, USA). The Chariker-Jeter ${ }^{\mathrm{TM}}$ (Smith and Nephew PLC, London, UK) wound sealing kit is also commercially available.

\section{Mechanism of action}

Subatmospheric pressure improves the wound environment, accelerating healing and reducing wound closure time. Animal studies have shown increased blood flow, increased rate of granulation tissue formation and proliferation, decreased tissue bacterial count, and increased randompattern flap survival. ${ }^{20,21}$ Clinical studies have also shown similar outcomes, most notably increased granulation tissue formation..$^{22}$ NPWT establishes and maintains a warm and moist microenvironment, which facilitates cell proliferation and migration, promoting angiogenesis and breakdown of necrotic tissue. ${ }^{23,24}$ Direct and indirect effects of the negative pressure are summarized in Table 1.25-34

\section{Portable NPWT}

NPWT technology has continued to evolve since its development in 1997. 20,22 The generic technology has lent itself to a variety of adaptations, most notably the creation of portable devices. ${ }^{35}$ Wounds have previously been managed with the large "hospital" NPWT devices in the home care setting, and portable versions may make this a more accessible option. ${ }^{36}$

Portable NPWT are similar to their older counterparts in their functionality. The two systems that are described most in the literature are the VAC Via ${ }^{\mathrm{TM}}$ Therapy system

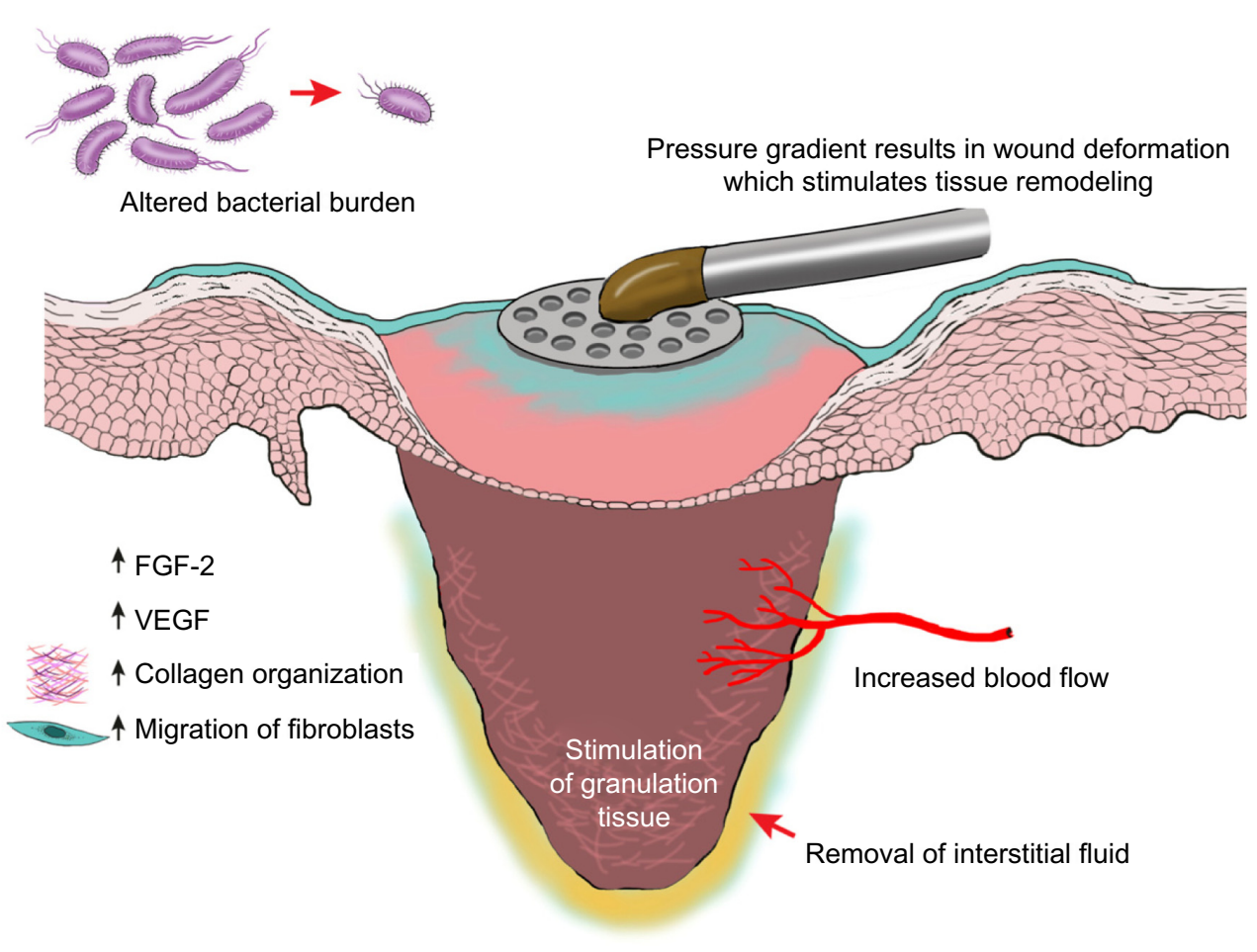

Figure I Proposed mechanisms of action of NPWT.

Abbreviations: FGF-2, fibroblast growth factor 2; VEGF, vascular endothelial growth factor; NPWT, negative pressure wound therapy. 
Table I The direct and indirect effects of negative pressure wound therapy

\section{Direct effects}

Maintains moist and warm environment, which hastens wound healing Pressure gradient promotes fluid transfer, reducing wound edema ${ }^{18,25}$

Pressure gradient results in wound deformation, which stimulates tissue remodeling 25,26

Indirect effects

Altered bacterial burden may promote wound healing ${ }^{20,27,28}$

Reduction in systemic mediators of inflammation, reduces inflammatory response $\mathrm{e}^{29,30}$

Increased blood flow promotes wound healing ${ }^{20,31-33}$

Changes in wound biochemistry:

- Mechanotransduction (resultant positive chemical activity from mechanical stimuli) and stretch increased the growth rate and migration of fibroblasts ${ }^{26}$

- Increased collagen organization ${ }^{34}$

- Increased expression of fibroblast growth factor 2 (FGF-2) ${ }^{34}$

- Increased expression of vascular endothelial growth factor (VEGF) ${ }^{34}$

(Kinetic Concepts, Inc.) and the PICO system (Smith and Nephew Healthcare, Hull, UK). These are both disposable and provide 7 days of uninterrupted NPWT utilizing a simplified user interface. Their small size allows them to be easily concealed, maximizing patient compliance and hastening patients' return to their premorbid state. ${ }^{37,38}$

\section{Risks and benefits of using NPWT devices in the home care setting}

The use of inpatient NPWT has been well reviewed in the literature and has been shown to reduce the length of stay. Portable NPWT systems allow patients to return home sooner, allowing for wound management in the community. ${ }^{39}$ Reduced length of stay is important for a number of reasons including resumption of normal life for the patient, maintenance of mobility, protection from hospital-acquired infections, and cost effectiveness of treatment. Patient satisfaction and compliance is also a major benefit to portable NPWT.

Risks of NPWT in the home care setting mimic those present as inpatients. These can be related to poor technique in the application of the system. This includes infrequent dressing changes, inadequate pressure application, a poorly sealed system or excoriation of skin due to incorrect foam sizing. ${ }^{18,40}$ With good technique and adequate patient management, these are avoidable complications. The main contraindication of NPWT (not specific to home care) is insufficient wound vascularization, which has shown to cause ischemia at the wound edges. ${ }^{18,41}$ Other complications include infection, skin irritation, pain during dressing changes, retention of sponge dressings in wounds, and bleeding. ${ }^{18,41}$
Undetected retention of sponge dressings in home care NPWT has been described in various case reports. ${ }^{42-44}$ It is advised that dressings should be changed every 48-72 hours to prevent granulation tissue infiltrating the sponge dressing. These changes are usually performed by a qualified health care professional. Dressings that are left in the wound after changes are regarded as foreign bodies and can cause infection. ${ }^{18}$ As multiple sponges are required in the management of one wound, a sensible solution to avoid this complication may be for a "surgical count" to be performed when a dressing is changed and all swabs that are removed checked for size. It may be more difficult to ensure this happens with home care NPWT when dressing changes are not made in a clinical environment.

Since patients treated with home care NPWT are seen less often by health care professionals as dressing changes can occur up to 3 days apart, they may be at higher risk of complications such as bleeding, infection, and necrosis. ${ }^{45}$ However, there are no reports of increased complications in home care compared with hospital care..$^{15,46,47}$ In fact, there is a suggestion that short-term complications are actually lower in NPWT-treated groups than in standard care. ${ }^{48}$ This may be due to reduced wound healing time resulting in less opportunity for infection, earlier mobilization, and patients' taking responsibility for their wound care.

Patients who are given a portable NPWT device need to be visited up to every 48 hours by trained medical staff. This is mainly for dressing changes, but also to check that their device usage is appropriate. ${ }^{1}$ Patients require an adequate knowledge and understanding in order to be comfortable with handling their device at home; complications may be overlooked without this. This incurs an additional cost and need for trained staff. Compared with bed days, portable therapy does seem to be less of a strain on these resources. Patients can be managed either by home visits or visits to the outpatient department for dressing changes. There does not yet seem to be a consensus on which of these options is better and is probably left to hospital or patient preference. ${ }^{35,47}$ Reported barriers to the use of portable NPWT in the UK include obtaining funding and clinicians' unfamiliarity with the application. ${ }^{35}$

\section{Efficacy studies}

The efficacy of NPWT has been investigated in a variety of situations including skin grafts, ulcers, sternal wounds, thoracotomy wounds, and chronic wounds. In the home care setting, the two main outcome variables that have been investigated are rate of closure and time in care. There are two main studies, by Philbeck et al and Schwien et al, that 
had large numbers of patients. ${ }^{49,50}$ Additionally, there are a few small studies that support these findings.

\section{Rate of closure}

Earlier work by Philbeck et $\mathrm{al}^{49}$ consisted of a retrospective case-control study (evidence level 3b) of 1,032 patients on the US Medicare database. This included 1,170 pressure ulcers that had not responded to previous treatment and were subsequently treated with NPWT at home. Their control group consisted of previously reported rates of wound closure when treated with saline-soaked gauze. A much smaller initial wound size $\left(4.3 \mathrm{~cm}^{2}\right)$ was reported in the control group, whilst the average wound size in their study group was $22.2 \mathrm{~cm}^{2}$. They concluded that a wound measuring $22.2 \mathrm{~cm}^{2}$ in the control group would have closed in 247 days. With the intervention of NPWT, this was reduced to 97 days. Multiple confounding factors include the differing average initial wound sizes and use of a retrospective control group.

Using a simultaneously treated control group, Pruksapong ${ }^{47}$ conducted a randomized control trial (evidence level 1b) comparing the use of portable $(n=15)$ NPWT with that of hospital ( $n=15)$ NPWT in patients with chronic wounds. The two groups were similar in age, sex, and wound type. They measured the rate of wound healing every 3 days for 12 days. There was a $1.57 \%$ per day wound healing in the patient treated in hospital compared with $1.59 \%$ per day in patients treated with the portable device; however, this was not statistically significant. Treatment of these wounds at home negated the costs of hospital stay, freeing up hospital beds. ${ }^{47}$ Therefore, NPWT may an acceptable option for managing chronic wounds with a similar outcome to hospital NPWT.

Begum and Papagiannopoulos ${ }^{12}$ prospectively looked at ten patients who were given portable NPWT for thoracotomy wounds intraoperatively and treated at home (evidence level 4). Dressing changes were managed by tissue viability nurses without anesthesia or analgesia. Good observational outcomes noted were as follows: early mobilization, no need for a second procedure to close, no pain, no odor, or inconvenience for the patient. The author particularly noted that dressing changes were uncomfortable if less frequent than 3-4 days owing to granulation tissue growing into the foam. Despite documenting the use and advantages of NPWT in the management of thoracotomy wounds, it is difficult to draw any conclusion owing to lack of measured outcomes.

\section{Time in care}

Prolonged inpatient stay in hospital is often a major cost of treatment. Initial purchase costs of nonportable NPWT machines are around $£ 15,000 / \mathrm{US} \$ 25,000$, not including dressing and canister costs at around £20/US \$35 each. ${ }^{1}$ Costs of portable NPWT systems are much less. The VAC $\mathrm{Via}^{\mathrm{TM}}$ system costs $£ 260 / \mathrm{US} \$ 450$ (including charger, carry bag, dressing kit, canister, and adhesive drapes), and the PICO system costs $£ 120 /$ US \$200 (including one battery pack and two dressings). ${ }^{1,35}$ Such portable systems are more cost effective than their inpatient counterparts, even when the expense of hospital bed days is excluded. Indeed, two studies have estimated a saving of around US \$8,500 for each patient treated with home care NPWT compared with normal wound dressing hospital care. ${ }^{49,51}$ A slightly lower, but still substantial saving of $£ 1,000 /$ US $\$ 1,600$ was recorded by Payne and Edwards ${ }^{35}$ for each patient treated with portable NPWT compared with inpatient NPWT.

Schwien et $\mathrm{al}^{50}$ retrospectively compared hospital admissions with home care NPWT in stages II and IV pressure ulcers $(n=60)$ to other wound care modalities (controls, $n=2,288$ ) (evidence level 3b). Thirty-five percent of NPWT patients experienced hospitalization compared with $48 \%$ in the comparison group $(P<0.05)$. Five percent then went on to rehospitalization owing to wound problems in the NPWT group compared with $14 \%$ in the control $(P<0.01)$. They saw no emergent care cases in the NPWT group compared with $8 \%$ in controls $(P=0.01)$. This study was the first to compare hospital admission and emergent care utilization amongst patients using NPWT and other wound care systems. Despite this, the nonrandomized data set used may not have been an adequate representation of the overall population owing to its source.

Banasiewicz et a ${ }^{15}$ performed a small, randomized control trial (evidence level 2b) comparing portable NPWT $(n=10)$ with standard dressings $(n=9)$ in the outpatient treatment of excised pilonidal sinus wounds. They found outpatient department visits were both more numerous and continued for longer in the standard dressing group compared with the NPWT group $(P<0.001)$. In a similar manner, they noted an average restoration to normal activity with NPWT at only 7.3 days, compared with 15.9 days in the standard dressing group $(P=0.002)$. There was also a highly significant reduction in pain after a week in the portable NPWT group $(P<0.001)$. The small size of this study and the variability in pilonidal sinuses make it difficult to compare with other efficacy studies. However, the benefit of using portable NPWT in these lesions is apparent.

Baharestani et $\mathrm{al}^{46}$ looked at the effect of delaying NPWT on the length of home health care. This was a nonrandomized retrospective analysis (evidence level 3b) of stage III/IV 
pressure ulcers ( $n=98)$ and surgical wounds $(n=464)$. Median treatment time was significantly less in the early treatment groups compared with late treatment groups $(P<0.0001)$. This translated into the total treatment time being increased by almost 1 day for every day NPWT was delayed. This supports the hypothesis that increasing the use of portable NPWT reduces wound closure time.

The primary outcome measure of wound care therapy is traditionally wound healing time. The study by Philbeck et $\mathrm{al}^{49}$ leads us to conclude that the use of NPWT at home results in faster wound healing than that of standard wound dressings. Furthermore, Pruksapong ${ }^{47}$ showed that the rate of wound healing with NPWT in the home care setting is at least as good as that with NPWT in the hospital setting. Comparing portable and hospital NPWT, however, the primary outcome measure of interest is length of hospital stay. This should be reduced with the use of portable devices. It appears that there are fewer hospital visits and admissions in NPWT-treated patients compared with standard treatment patients. There is no explicit evidence showing reduced hospital stay in portable versus hospital NPWT. However, if patients are discharged on portable NPWT rather than remain in hospital until completed, it follows that hospital stay will be reduced. This is the biggest advantage of portable NPWT and one that will have the greatest economic benefit of community-based wound care, as shown in the UK. ${ }^{51}$

\section{Patient perspectives}

The success and efficacy of this treatment also depends on patient experiences. The main determinants in patient-focused reports include pain, anxiety, smell, and ease of use.

Pain during NPWT is most likely to occur during dressing changes, and this also applies to portable NPWT. Dressing changes beyond 3-4 days apart may be uncomfortable because of the growth of granulation tissue into the dressing. ${ }^{12}$ In a randomized case-control study $(n=19)$ (evidence level 3b) Banasiewicz et al assessed pain on days 1, 3, 4, and 7 of NPWT therapy and reported significantly less pain after day 3 in patients treated with portable NPWT compared with standard dressings $(P<0.01) .{ }^{15}$ This article used the validated visual analog scale (VAS) to assess pain, although conclusions are limited by the small study number. ${ }^{52} \mathrm{~A}$ similar-sized, noncomparative, pilot observational study $(n=16)$ (evidence level 4) found most patients reported minor or no pain during NPWT of postamputation wounds and foot ulcers. ${ }^{53}$ This study asked patients to verbalize their pain rating at activation of NPWT and dressing removal as one of "none", "minor", "average", "moderate", or "severe". Here, more reliable conclusions can be drawn from the use of VAS than from verbal description of pain. However, a larger study that utilizes the VAS is required. The use of alternative dressings such as gauze or silicone in place of the usual sponge dressing may be favored for causing less pain with NPWT. ${ }^{54,55}$

Anxiety whilst using NPWT has been noted in one casecontrol study (evidence level 3b) by Keskin et al. Hospital NPWT was compared with standard care of traumatic lower limb wounds and it was found that NPWT patients had significantly higher levels of anxiety $(P<0.001) .{ }^{56}$ In addition, these patients also experienced a restriction of mobility due to their nonportable NPWT, which may have contributed to these anxiety levels. With increased mobility using portable NPWT, it seems reasonable to suggest that lower anxiety levels would be seen.

Smell has also been noted in some of the literature. One focus group reported that patients were satisfied with the effectiveness of NPWT, although embarrassment was felt because of smell. ${ }^{57}$ Conversely, in a ten-patient case series (evidence level 4), Begum and Papagiannopoulos reported simply that "no odor or inconvenience with home care NPWT was experienced." 12

There is a possibility that some patients will find it difficult to understand how to manage their portable NPWT equipment between dressing changes. ${ }^{58}$ There is no accepted measure of ease of use, and all reports of this are solely patient opinion. Reports indicate that, on the whole, patients find portable NPWT machines easy to use. ${ }^{35,53}$ Moffat et al reported some difficulty with use, although this was counterbalanced with "general positivity" of patients on portable NPWT. ${ }^{59}$ There may be a disadvantage in the need to carry the portable pump, although reports show that pumps are small enough to conceal and do not interfere with daily life. ${ }^{1,9,12}$ Difficulty of use can be avoided with proper patient counseling given before discharge with portable NPWT. Additionally, as dressing changes require regular visits from a health care professional, these can also be utilized to consolidate the patients' understanding of the device.

No studies comparing quality of life in patients undergoing NPWT therapy at hospital versus home were found. Hurd et al ${ }^{60}$ noted that $81 \%(263 / 326)$ of patients were "pleased" with portable therapy and only $3 \%$ (8/326) dissatisfied; however, they did not assess satisfaction in their hospital NPWT group and thus could not compare. Overall, there is limited literature on quality of life in NPWT in the home care setting. Knowledge in this area is restricted to the case reports and patient opinion pieces discussed, which do suggest an improved quality of life with portable NPWT. 


\section{Conclusion}

The benefits of subatmospheric pressure in wound healing are well established. However, there remains no 1a study demonstrating increased efficacy of portable NPWT over conventional wound dressing systems. Randomized controlled trials within the literature are limited to select wound types and investigate primary and secondary end points that are similar in nature. Nevertheless, the worth of hospital NPWT has been shown in a variety of wounds in a number of studies. ${ }^{2,3,8,13,14}$ Comparisons of hospital versus home NPWT are limited by the nature of wounds that would be selected for each. Hurd et $\mathrm{l}^{60}$ give a prime example of this issue with their hospital NPWT patients having both larger wound volume and higher exudate levels. These are two important factors in wound closure that need to be similar between groups to allow a valid comparison.

The development of portable NPWT is an encouraging innovation in wound care technology. Extending the benefits of NPWT therapy to outpatients and the community is both possible and potentially more beneficial. Effectiveness of portable NPWT has shown to be better than standard dressings and at least as good as hospital NPWT in rate of wound closure. Complications of home care NPWT are no more likely or serious compared with inpatient NPWT, but proper patient counseling and education must be given. The benefits of portable over inpatient NPWT include reduced hospital stay, increased patient satisfaction and compliance, possibly due to shortened treatment times. Less hospital contact time permits a return to normal life for the patient. The potential reduction in anxiety levels and perceived control over illness could further benefit recovery in certain patients. Additionally, there are major cost benefits to using portable NPWT compared with inpatient NPWT.

\section{Disclosure}

The authors report no conflicts of interest in this work.

\section{References}

1. Ali Hussain M. Life can't be any easier than this - introduction of the portable and disposable VAC machines. Mod Plast Surg. 2012;02(02): 24-27.

2. Fleischmann W, Strecker W, Bombelli M, Kinzl L. [Vacuum sealing as treatment of soft tissue damage in open fractures]. Unfallchirurg. 1993;96(9):488-492. German.

3. Capobianco CM, Zgonis T. An overview of negative pressure wound therapy for the lower extremity. Clin Podiatr Med Surg. 2009;26(4): 619-631.

4. Deva AK, Siu C, Nettle WJ. Vacuum-assisted closure of a sacral pressure sore. J Wound Care. 1997;6(7):311-312.

5. Baynham SA, Kohlman P, Katner HP. Treating stage IV pressure ulcers with negative pressure therapy: a case report. Ostomy Wound Manage. 1999;45(4):28-32, 34-35.
6. Kovacs L, Kloppel M, Geishauser S, Schmiedl S, Biemer E. Vacuum sealing: a new and promising regimen in the therapy of radiation ulcers. Br J Surg. 1998;85:70.

7. DeFranzo AJ, Marks MW, Argenta LC, Genecov DG. Vacuum-assisted closure for the treatment of degloving injuries. Plast Reconstr Surg. 1999;104(7):2145-2148.

8. Fleischmann W, Lang E, Kinzl L. [Vacuum assisted wound closure after dermatofasciotomy of the lower extremity]. Unfallchirurg. 1996;99(4):283-287. German.

9. Awad T, Butcher M. Handling the sequelae of breast cancer treatment: use of NPWT to enhance patient independence. $J$ Wound Care. 2013;22(3):162, 164-166.

10. Bullough L, Wilkinson D, Burns S, Wan L. Changing wound care protocols to reduce postoperative caesarean section and readmission. Wounds (UK). 2014;10(1):72-77.

11. Obdeijn MC, de Lange MY, Lichtendahl DH, de Boer WJ. Vacuumassisted closure in the treatment of poststernotomy mediastinitis. Ann Thorac Surg. 1999;68(6):2358-2360.

12. Begum SS, Papagiannopoulos K. The use of vacuum-assisted wound closure therapy in thoracic operations. Ann Thorac Surg. 2012;94(6): 1835-1839; discussion 1839-1840.

13. Dumville JC, Munson C. Negative pressure wound therapy for partialthickness burns. Cochrane Database Syst Rev. 2012;12:CD006215.

14. Smith LA, Barker DE, Chase CW, Somberg LB, Brock WB, Burns RP. Vacuum pack technique of temporary abdominal closure: a four-year experience. Am Surg. 1997;63(12):1102-1107; discussion 1107-1108.

15. Banasiewicz T, Bobkiewicz A, Borejsza-Wysocki M, et al. Portable VAC therapy improve the results of the treatment of the pilonidal sinus randomized prospective study. Pol Przegl Chir. 2013;85(7):371-376.

16. Matatov T, Reddy KN, Doucet LD, Zhao CX, Zhang WW. Experience with a new negative pressure incision management system in prevention of groin wound infection in vascular surgery patients. J Vasc Surg. 2013;57(3):791-795.

17. OCEBM Levels of Evidence Working Group. "The Oxford 2011 Levels of Evidence". Available from: http://www.cebm.net/wp-content/ uploads/2014/06/CEBM-Levels-of-Evidence-2.1.pdf. Accessed September 30, 2014.

18. Venturi ML, Attinger CE, Mesbahi AN, Hess CL, Graw KS. Mechanisms and clinical applications of the Vacuum-Assisted Closure (VAC) Device. Am J Clin Dermatol. 2005;6(3):185-194.

19. Ubbink DT, Westerbos SJ, Nelson EA, Vermeulen H. A systematic review of topical negative pressure therapy for acute and chronic wounds. Br J Surg. 2008;95(6):685-692.

20. Morykwas MJ, Argenta LC, Shelton-Brown EI, McGuirt W. Vacuumassisted closure: a new method for wound control and treatment: animal studies and basic foundation. Ann Plast Surg. 1997;38(6):553-562.

21. Scherer SS, Pietramaggiori G, Mathews JC, Prsa MJ, Huang S, Orgill DP. The mechanism of action of the vacuum-assisted closure device. Plast Reconstr Surg. 2008;122(3):786-797.

22. Argenta LC, Morykwas MJ. Vacuum-assisted closure: a new method for wound control and treatment: clinical experience. Ann Plast Surg. 1997;38(6):563-576; discussion 577.

23. Orgill DP, Manders EK, Sumpio BE, et al. The mechanisms of action of vacuum assisted closure: more to learn. Surgery. 2009;146(1):40-51.

24. McColl D, MacDougall M, Watret L, Connolly P. Monitoring moisture without disturbing the wound dressing. Wounds (UK). 2009;5(3): 94-99.

25. Urschel JD, Scott PG, Williams HT. The effect of mechanical stress on soft and hard tissue repair; a review. Br J Plast Surg. 1988;41(2): 182-186.

26. Nishimura K, Blume P, Ohgi S, Sumpio BE. Effect of different frequencies of tensile strain on human dermal fibroblast proliferation and survival. Wound Repair Regen. 15(5):646-656.

27. Mouës CM, Vos MC, van den Bemd GJ, Stijnen T, Hovius SER. Bacterial load in relation to vacuum-assisted closure wound therapy: a prospective randomized trial. Wound Repair Regen. 12(1):11-17. 
28. Mouës CM, van den Bemd GJ, Heule F, Hovius SER. Comparing conventional gauze therapy to vacuum-assisted closure wound therapy: a prospective randomised trial. J Plast Reconstr Aesthet Surg. 2007;60(6):672-681.

29. Norbury K, Kieswetter K. Vacuum-assisted closure therapy attenuates the inflammatory response in a porcine acute wound healing model. Wounds. 2007;19(4). Available from: http://www.woundsresearch.com/ article/7180. Accessed August 13, 2014.

30. Greene AK, Puder M, Roy R, et al. Microdeformational wound therapy: effects on angiogenesis and matrix metalloproteinases in chronic wounds of 3 debilitated patients. Ann Plast Surg. 2006;56(4):418-422.

31. Kairinos N, Voogd AM, Botha PH, et al. Negative-pressure wound therapy II: negative-pressure wound therapy and increased perfusion. Just an illusion? Plast Reconstr Surg. 2009;123(2):601-612.

32. Ichioka S, Watanabe H, Sekiya N, Shibata M, Nakatsuka T. A technique to visualize wound bed microcirculation and the acute effect of negative pressure. Wound Repair Regen. 2008;16(3):460-465.

33. Morykwas MJ, Faler BJ, Pearce DJ, Argenta LC. Effects of varying levels of subatmospheric pressure on the rate of granulation tissue formation in experimental wounds in swine. Ann Plast Surg. 2001;47(5): 547-551.

34. Jacobs S, Simhaee DA, Marsano A, Fomovsky GM, Niedt G, Wu JK. Efficacy and mechanisms of vacuum-assisted closure (VAC) therapy in promoting wound healing: a rodent model. J Plast Reconstr Aesthet Surg. 2009;62(10):1331-1338.

35. Payne C, Edwards D. Application of the single use negative pressure wound therapy device (PICO) on a heterogeneous group of surgical and traumatic wounds. Eplasty. 2014;14:e20.

36. Guy H, Grothier L. Using negative pressure therapy in wound healing. Nurs Times. 2012;108(36):16-20. Available from: http://www. nursingtimes.net/Journals/2012/09/06/p/s/v/040912Using-negativepressure-therapy-in-wound-healing-NEW.pdf. Accessed September 30, 2014.

37. Kinetic Concepts, Inc. (KCI). VAC Via ${ }^{\mathrm{TM}}$ Negative Pressure Wound Therapy System. Available from: http://www.kcil.com/cs/ Satellite?c=KCI_Product_C\&childpagename=KCI1\%2FKCILayout $\&$ cid $=1229636483749 \& \mathrm{p}=1229538260417 \&$ packedargs $=$ locale $\% 3 \mathrm{D}$ en_US\&pagename=KCI1Wrapper. Accessed August 3, 2014.

38. Smith and Nephew Corporate. Introducing PICO: single Use Negative Pressure Wound Therapy NPWT. Available from: http://www.smithnephew.com/key-products/advanced-wound-management/pico/. Accessed August 3, 2014.

39. Khanbhai M, Fosah R, Oddy MJ, Richards T. Disposable NPWT device to facilitate early patient discharge following complex DFU. $J$ Wound Care. 2012;21(4):180, 182.

40. Vacuum-Assisted Closure for the Management of Wounds: An Accelerated Systematic Review [dissertation]. Centre for Reviews and Dissemination: UK; 2003.

41. Attinger CE, Janis JE, Steinberg J, Schwartz J, Al-Attar A, Couch K. Clinical approach to wounds: débridement and wound bed preparation including the use of dressings and wound-healing adjuvants. Plast Reconstr Surg. 2006;117(Suppl 7):72S-109S.

42. Beral D, Adair R, Peckham-Cooper A, Tolan D, Botterill I. Chronic wound sepsis due to retained vacuum assisted closure foam. $B M J$ 2009;338:b2269.
43. Fox A, Tadros A, Perks AGB. An unusual complication of Vacuum Assisted Closure in the treatment of a pressure ulcer. $J$ Wound Care. 2004;13(8):344-345.

44. Caniano DA, Ruth B, Teich S. Wound management with vacuumassisted closure: experience in 51 pediatric patients. $J$ Pediatr Surg. 2005;40(1):128-132.

45. White RA, Miki RA, Kazmier P, Anglen JO. Vacuum-assisted closure complicated by erosion and hemorrhage of the anterior tibial artery. J Orthop Trauma. 2005;19(1):56-59.

46. Baharestani MM, Houliston-Otto DB, Barnes S. Early versus late initiation of negative pressure wound therapy: examining the impact on home care length of stay. Ostomy Wound Manage. 2008;54(11):48-53.

47. Pruksapong C. Efficacy of portable vacuum dressing in chronic wound care: a prospective randomized control trial. J Med Assoc Thai. 2011;94(10):1212-1217.

48. Huddleston EM. Unlocking the potential of NPWT. Negat Press Wound Ther. 2014;1(2):76-80. 5th International NPWT Expert Meeting Report; March 21-22, 2014, Frankfurt.

49. Philbeck TE, Whittington KT, Millsap MH, Briones RB, Wight DG, Schroeder WJ. The clinical and cost effectiveness of externally applied negative pressure wound therapy in the treatment of wounds in home healthcare Medicare patients. Ostomy Wound Manage. 1999;45(11): 41-50.

50. Schwien T, Gilbert J, Lang C. Pressure ulcer prevalence and the role of negative pressure wound therapy in home health quality outcomes. Ostomy Wound Manage. 2005;51(9):47-60.

51. Dowsett C, Davis L, Henderson V, Searle R. The economic benefits of negative pressure wound therapy in community-based wound care in the NHS. Int Wound J. 2012;9(5):544-552.

52. Carlsson AM. Assessment of chronic pain. I. Aspects of the reliability and validity of the visual analogue scale. Pain. 1983;16(1):87-101.

53. Stansby G, Wealleans V, Wilson L, Morrow D, Gooday C, Dhatariya K. Clinical experience of a new NPWT system in diabetic foot ulcers and post-amputation wounds. $J$ Wound Care. 2010;19(11):496, 498-502.

54. Hurd T, Chadwick P, Cote J, Cockwill J, Mole TR, Smith JM. Impact of gauze-based NPWT on the patient and nursing experience in the treatment of challenging wounds. Int Wound J. 2010;7(6):448-455.

55. Téot L, Lambert L, Ourabah Z, et al. Use of topical negative pressure with a lipidocolloid dressing: results of a clinical evaluation. $J$ Wound Care. 2006;15(8):355-338.

56. Keskin M, Karabekmez FE, Yilmaz E, Tosun Z, Savaci N. Vacuumassisted closure of wounds and anxiety. Scand J Plast Reconstr Surg Hand Surg. 2008;42(4):202-205.

57. Abbotts J. Patients' views on topical negative pressure: "effective but smelly." Br J Nurs. 19(20):S37-S41.

58. Fagerdahl A-M, Boström L, Ulfvarson J, Ottosson C. Risk factors for unsuccessful treatment and complications with negative pressure wound therapy. Wounds. 2012;24(6):168-177.

59. Moffatt CJ, Mapplebeck L, Murray S, Morgan PA. The experience of patients with complex wounds and the use of NPWT in a home-care setting. J Wound Care. 2011;20(11):512, 514, 516, passim.

60. Hurd T, Trueman P, Rossington A. Use of a portable, single-use negative pressure wound therapy device in home care patients with low to moderately exuding wounds: a case series. Ostomy Wound Manage. 2014;60(3):30-36.
Smart Homecare Technology and TeleHealth

\section{Publish your work in this journal}

Smart Homecare Technology and TeleHealth is an international, peer-reviewed, open access online journal publishing original research, reviews, editorials and commentaries on the application of technology to support people and patients at home and in assisted living centers to optimize healthcare and management resources. Specific topics in the journal include: Development and application of

\section{Dovepress}

devices within the home and embedded in appliances; Healthcare provider communication and education tools; and drug ordering and adherence. The manuscript management system is completely online and includes a very quick and fair peer-review system, which is all easy to use. Visit http://www.dovepress.com/ testimonials.php to read real quotes from published authors. 